Accepted version of

Boud, D. (2015). Feedback: ensuring it leads to enhanced learning. The Clinical Teacher, 12, 3-7.

DOI: $10.1111 /$ tct.12345

\title{
Feedback: ensuring it leads to enhanced learning
}

Feedback involves much more than providing potentially useful information to learners about their work. The challenge is now on how to engage with learners in ways likely to result in discernable change and the nature of the conditions necessary to ensure that feedback discussions are likely to be acted upon. The main aspects of assessment and feedback drawn on here are those that focus on how assessment and feedback can contribute to the ongoing learning of students (and indeed all health professionals) and the need for feedback to actually influence what students do.

\section{Defining feedback}

Higher education programmes are more frequently criticised in student surveys for deficiencies in assessment and feedback than any other aspect. This has resulted in renewed interest in what feedback is and how it can work effectively. In particular, it has led to recognition that feedback in clinical settings, just like feedback in any other context, must be characterised not solely in terms of inputs that are made, but effects that result. The definition of feedback in Box 1 highlights this change in thinking. Teachers, or others offering feedback information, can therefore only confirm that learning has resulted from information provided if students act on it, to complete a feedback loop. ${ }^{2}$

\section{Box 1: Definition of feedback}

'...a process whereby learners obtain information about their work in order to appreciate the similarities and differences between the appropriate standards for any given work, and the qualities of the work itself, in order to generate improved work. ${ }^{1}$

\section{Changing ideas of feedback}

When used in its original disciplines, for example in systems engineering, feedback describes what happens when information from a system is reinserted into the system to regulate its behaviour. Determining if feedback has occurred involves observing a change in response of the system. Commonly, when the idea of feedback is transferred to the educational context, the notion of providing information with the intention of changing the system (in this case, the learner) is retained, but the notion of seeking to observe a change in output is often missing. It is assumed that the desired change will occur or that if students could pay sufficient attention to the input (such as comments from a tutor), then the desired learning outcomes will be produced. Without knowledge of the effects, teachers cannot be sure if the feedback loop is completed, and thus feedback -in the sense understood for example by engineers - may not have occurred. They have no basis on which to judge whether their input is worthwhile. A signal has been transmitted (input from teachers), but we have no knowledge that it has been received or acted upon (through change in students). Attending to this input is a necessary but not sufficient condition for 'feedback' to have an effect.

The basic idea of feedback: Feedback Mark 1 
To ensure that feedback works for learning, we can start by making sure that there is evidence that the feedback loop has been completed. That is, information provided to students has been taken up and led to some desirable change in practice. This idea of feedback has been termed Feedback Mark 1. ${ }^{1}$ The implications of this simple application of what feedback means are substantial. In order to identify an activity as feedback teachers need to detect that information provided to learners was firstly apprehended and subsequently that it resulted in some kind of change: that is, it has had an impact on their learning. For this to be identifiable, teachers must have knowledge of the subsequent performance of the student so that a change can be noticed. Feedback is therefore not an act that occurs at a single point in time-at the point of transmission of information from teacher to student, but one completed over time-when knowledge of subsequent work is communicated from student to teacher, or the teacher observes the student again later.

Unfortunately, such a practice of following students' work over time cannot always be achieved, particularly in busy clinical environments and when students (and trainees) are moved frequently from one location to another. Indeed, in many clinical settings it is difficult to ensure that students are observed at all let alone receive any useful information about their practice. Such settings may preclude the operation of any kind of feedback, and their inclusion as part of an educational experience needs to be justified in some other way.

Any reframing of feedback must also take into account the agency of learners and how they respond to the input of others. Recognising this active role of learners implies that for them to act effectively on the input of others, certain conditions must be met (Box 2).

\section{A responsive view of feedback: Feedback Mark 2}

A more sustainable view of feedback involves a more central role for learners; in this learners are no longer merely recipients of information, but are active agents seeking and using information from a variety of sources. This has been termed Feedback Mark $2^{1}$ Two-way interactions between giver and receiver, and the involvement of peers, non-human sources and practitioners as well as teachers are required. Other parties are used not simply as information sources, but as a means whereby learners can calibrate their own judgements and create for themselves the expertise needed for further study and performance. ${ }^{3}$ That is, how do a student's practices match those of an accomplished clinician, and what is needed to bring this up to the required performance?

This view sees feedback as a key feature of the curriculum that responds to and drives learning. It is not separate, but is an integral part of all learning processes. Feedback becomes a design feature of courses, and all clinical placements, located to enable sufficient practice to be had, for feedback loops to be completed and effectiveness in self-judgement developed as a learning outcome. It is also a strategy that can be deployed by learners as and when it is needed for their own learning paths. This dual nature of feedback acknowledges that there needs to be a disposition on the part of learners to utilise what is available to them in clinical settings and that they develop the ability to realise the potential of the environment as a place of learning. The conditions needed for this (Box 2) can be identified from the need for learners to understand and attend to the input and use it both to act in the current context and develop their capacity to act further beyond the immediate situation.

\section{Box 2: Conditions required for optimal feedback}

- Learners must value the input

- There must be some kind of dialogue between giver and receiver ${ }^{4}$ to appreciate the criteria and standards being applied

- Trust must be built between giver and receiver so that the learner invests the time and effort required to act on information given ${ }^{5}$ 
- Learners must develop their capacity to calibrate their own judgements and appreciate the qualities of their work and how it might otherwise be improved

In most situations, the clinician at hand necessarily makes the initial judgement call no matter what their level of experience. Learners therefore need to quickly develop an understanding of what they know and don't know, and what they can do and not do. They are helped to develop these skills of self-assessment (or self-evaluation) by teachers 'providing direct authentic evaluative experience for students'. ${ }^{2}$ Students require opportunities to make specific judgements about particular work they have undertaken (for example, in communication skills training students are asked for their opinion of their own performance and what they could change to improve). As in the development of any form of expertise, such skills have to be developed over time. Even multiple examples of self-assessment activity deployed from time to time may have relatively little influence. Students encounter new domains of clinical practice that require new behaviours, and these changes are disruptive. It is unlikely that without support their judgement will improve continuously as novel situations are encountered.

The role of feedback in the development of judgement is therefore particularly important. ${ }^{5}$ Students need to have ways of knowing whether their judgements are realistic and be able to assess these in the light of evidence. Through such calibration against others' judgements (tutors, peers, practitioners, even patients), learners can identify the areas in which they need to improve and see shifts in their ability over time. In addition, learners need to be aware of the outcomes they are aiming at and the criteria (or standards) against which they are being assessed, leading to three requirements for feedback that influences learning (Box 3). Standards not only need to be explicit, and derived from statements of competencies included in curriculum and regulatory requirements, but students also need to appreciate how these standards are manifest in work of the kind in which they are engaged. Relating these standards to one's own work needs an ability to see in one's own work behavioural indications of achievement. Finally, closing the gap requires opportunities for subsequent practice to show this knowledge translated into action.

Box 3: Requirements for effective feedback that influences learning ${ }^{2}$

1. Knowledge of appropriate standards (by learner and teacher)

2. Comparison of one's own work with these standards

3. Taking of action to close the gap between the two

A particular feature of learning and teaching to aid this process is for student judgements to be compared to those of experienced practitioners of the kind of work being considered. Noticing the qualities of work in one's own practice is difficult and the availability of the judgements of others with respect to the very criteria needed to judge one's own work is important. In such situations discrepancies between students' judgement and that of the expert are important pointers for raising students' awareness about what they need to do to subsequently improve their clinical practice.

\section{Characteristics of good feedback information}

The extent to which feedback information serves to reduce the gap between current and desired performance is partly dependent on the level at which the feedback operates. ${ }^{6}$ Students respond in different ways to different types of information so the information needs to be tailored to what students need to do with it. Some information and some ways in which it is framed are demotivating and act to inhibit learning. ${ }^{7}$ Hattie's model ${ }^{6}$ derived from a strong evidence base, proposes that feedback can be directed at four different levels of operation of the student and that feedback may well be ineffective if directed at an inappropriate level (Box 4). The responses that students make are dependent in part on the 
focus and type of feedback they get. If the focus is inappropriate to the needs of the student, the information can be ineffective because the student is unable or unwilling to transform the information into action where it is needed. A simple but regrettable example of this is the inadvertent humiliation of learners in the health professions. ${ }^{8}$.

\section{Box 4: Hattie's four levels of feedback ${ }^{10}$}

\section{Task focussed (FT)}

Task focused information emphasizes how well a task has been done, identifying when statements are incorrect or contestable, and suggesting that more or different information is necessary to complete the task or do it better. It is most powerful when learning problems are about faulty interpretations, not lack of information. Comments at the task level do not necessarily generalize to other tasks.

\section{Process focussed (FP)}

Process focused comments are addressed to the processes used when completing tasks or to those used to make connections across tasks to broaden or expand tasks into new areas. In comments of this kind, learners are assisted to create meaning and relate to the connections between concepts, to how students' cognitive processes are being developed, and to their application to other more difficult or untried tasks. One mode of process focused feedback tackles students' strategies for error detection, which can range from finding a different way to express an issue to self-diagnosis by the learners of their misunderstanding. Comments at the process level can be more effective than at the task level for enhancing deeper learning. For example, asking a student to explain to a peer, will sometimes trigger a realization that they have omitted something important.

\section{Self-regulation focussed (FR)}

Self-regulation focused comments have the greatest potential to influence what students do. Feedback is a two way process and one that, under the right circumstances, should originate within the learner. Self regulation focussed comments have at least six aspects that mediate the effectiveness of feedback: the capacity to create 'internal' feedback; the ability to self-assess; a willingness to invest effort into seeking and dealing with feedback information; a degree of confidence or certainty in the correctness of the response; attributions about success or failure; level of proficiency at seeking help. Self-regulation focused input may take the form of posing questions rather than giving information.

\section{Person (self) focussed (FS)}

Person-focused feedback is directed at personal attributes, such as understanding, intelligence and ability and can often be the least effective. It usually contains little or no task-related information. Examples of person-focused statements are 'You are so clever'; 'You have a very interesting approach to things'. For this reason, person focused feedback is usually ineffective: it doesn't include information on matters that learners can see that they can change. Such praise on its own, while highly valued by many students, does not translate into more engagement with, or commitment to, learning goals, does not promote selfefficacy, nor lead to greater understanding about learning tasks. Negative person focused comments-eg. "you weren't being very professional there" can potentially have a negative effect on learning. More considered person-focused feedback may however be used to build trust between the learner and a supervising professional.

\section{Summary}

In summary, what emerges from recent research and scholarship on feedback are the following points:

- Learning involves bridging the gap between desired and actual performance 
- Feedback comments must primarily be judged on their effects on learning and performance

- It is necessary to look beyond the immediate task: acts of assessment must be designed to leave learners better equipped to learn further

- Learners need to develop a view about what constitutes quality work if they are to be able to demonstrate it for themselves

- Feedback is not a unilateral act by tutors or trainers, but a set of interlinked activities

- Students need always to be positioned by tutors and other staff as pro-active learners who can initiate feedback-seeking behaviour.

- Knowledge of the learner's desires and expectations is needed for effective input

- Effective learning requires dialogue

- The overriding purpose of feedback practices is the refinement of learner's capacity use of information to judge themselves in similar situations

- Inputs from tutors are important as they can open up or close down learning possibilities

Feedback processes can make a substantial on learning, but only if they are understood in a more dynamic way than traditional recipes for feedback comments have implied.

\section{Acknowledgement}

The author would like to particularly thank Jill Thistlethwaite without whom this paper would not have come to have been written.

\section{References}

${ }^{1}$ Boud D, Molloy, E. Rethinking models of feedback for learning: the challenge of design. Assessment and Evaluation in Higher Education 2013; 38: 698-712.

${ }^{2}$ Sadler D R. Formative assessment and the design of instructional systems, Instructional Science 1989; 18(2): 119-44.

${ }^{3}$ Boud D, Lawson R, Thompson D. Does student engagement in self-assessment calibrate their judgement over time? Assessment and Evaluation in Higher Education 2013; 38: 941-956.

${ }^{4}$ Nicol D. From monologue to dialogue: improving written feedback in mass higher education, Assessment and Evaluation in Higher Education 2010; 35(5): 501-517.

${ }^{5}$ Carless D. Trust, distrust and their impact on assessment reform. Assessment \& Evaluation in Higher Education 2009; 34: 79-89.

${ }^{6}$ Hattie J, Timperley, H. The power of feedback. Review of Educational Research 2008; 77: 81-112.

${ }^{7}$ Shute V J. Focus on formative feedback. Review of Educational Research 2008; 78: 153- 189.

${ }^{8}$ Lempp H, Seale C. The hidden curriculum in undergraduate medical education: qualitative study of medical students' perception of teaching. BMJ 2004; 329: 770-773.

9 Seabrook A M. Clinical students' initial reports of the educational climate in a single medical school. Medical Education 2004; 38: 659-6

${ }^{10}$ Jolly B, Boud D. Written feedback: what is it good for and how can we do it well? In Boud, D. and Molloy, E. (Eds.). Feedback in Higher and Professional Education. London: Routledge, 2013, pp.104-124. 